\title{
Analysis of the genetic polymorphism between three Streptococcus thermophilus strains by comparing their physical and genetic organization
}

\author{
Yvonne Roussel,† Florence Bourgoin, Gérard Guédon, Mireille Pébay \\ and Bernard Decaris
}

\begin{abstract}
Author for correspondence: Bernard Decaris. Tel: +333839121 93. Fax: +33383912500 . e-mail: decaris@nancy.inra.fr
\end{abstract}

Laboratoire de Génétique et Microbiologie, UA INRA, Université Henri Poincaré, BP 23954506 Vandœuvrelès-Nancy Cedex, France
The physical maps of Streptococcus thermophilus CNRZ368 and NST2280 strains were constructed by analysing PFGE patterns obtained with the low-frequencycutting enzymes Smal, BssHII and Sfil. Their chromosomes are 1864 and 1840 kb circular molecules, respectively. Comparison of their physical maps with that of the reference A054 strain revealed a relatively conserved organization of the restriction sites. Three variable regions were detected with the map of CNRZ368 whereas 15 were found with the map of NST2280. To construct the genetic maps, probes corresponding to 10 single-copy genes, the rrn genes and the insertion sequences IS1191, IS981 and ISS1 were hybridized to Southern blots of chromosomal DNA digested with the different mapping enzymes. Comparison of the genetic maps of the three strains showed a conserved location of the mapped single-copy genes. However, six rrn loci were present in the chromosome of A054 and CNRZ368 whereas five were present in the NST2280 chromosome. A polymorphism was also found in the copy number of the insertion sequences between the three strains.

Keywords: Streptococcus thermophilus, physical and genetic map, variable region, IS element

\section{INTRODUCTION}

Streptococcus thermophilus is a Gram-positive bacterium used as a starter in the manufacture of fermented dairy products such as yoghurt and some hard cheeses. Despite its importance in the dairy industry, little is known about the genetic diversity within this species. The genetic variability within $S$. thermophilus was first investigated by analysis of restriction fragment length polymorphism. Analysis of patterns produced after digestion with high-frequency-cutting endonucleases and separation by conventional agarose gel electrophoresis revealed the existence of a great deal of genetic polymorphism among $S$. thermophilus strains (Colmin et al., 1987, 1991; Salzano et al., 1993). The intraspecific polymorphism of precise regions of the genome was also demonstrated by hybridization with an rDNA fragment

†Present address: Institute of Food Research, Norwich Laboratory, Norwich Research Park, Colney, Norwich NR4 7UA, UK.

Abbreviations: CHEF, contour-clamped homogeneous electric field; IS, insertion sequence.
(Pébay et al., 1992a) and with a DNA fragment specific to the two closely related species $S$. thermophilus and Streptococcus salivarius (Colmin et al., 1991). However, the extent of the genetic polymorphism in the $S$. thermophilus species and its genetic background have not yet been clarified.

Pulsed-field gel electrophoresis (PFGE), which enables separation of large DNA fragments, provides an alternative and complementary tool for studying genetic polymorphism among bacterial strains. Strains of the same species can be identified and characterized by comparing PFGE fingerprints produced by digestion of genomic DNA with rare-cutting enzymes and resolution of resultant fragments by PFGE. SmaI and NotI fingerprints were used to characterize strains of $S$. thermophilus (Salzano et al., 1993). In order to correlate the differences observed in fingerprints with major changes in the chromosome structure, the macrorestriction fragments have to be aligned in a physical map. A chromosomal map of $S$. thermophilus A054 was constructed (Roussel et al., 1994). The genome of the A054 
strain is a unique circular chromosome of $1824 \mathrm{~kb}$. Twenty-three genetic markers, including 11 single-copy genes, the six rRNA operons and six tRNA genes, were located on the restriction map by performing Southern hybridizations with specific probes.

In the present work, the PFGE approach was used to analyse genomic diversity within the $S$. thermophilus species. This report describes the physical and genetic organization of the chromosomes of two additional strains of S. thermophilus, CNRZ368 and NST2280. Alignment of the chromosomal maps of these two strains with that of strain A054 identified and located variable physical regions. Ten probes specific to single genes, rDNA fragments and internal sequences of the three insertion sequences IS1191, IS981 and ISS1 were used in Southern hybridizations for the construction of genetic maps.

Comparison of the genetic maps of the three strains revealed an important similarity in the genome organization of the three strains. However, six rrn loci are present in the chromosome of A054 and CNRZ368 whereas five are present in the NST2280 chromosome. Moroever, the IS1191, IS981 and ISS1 elements were found in different copy numbers in the chromosome of the three strains.

\section{METHODS}

Bacterial strains and gene probes. S. thermophilus A054, which originated from the dairy industry, was provided by A.
Mercenier (Institut Pasteur, Lille, France). The CNRZ368 strain was obtained from the culture collection of the Centre National de la Recherche Zootechnique (France) and the NST2280 strain descended from the industrial NST7 strain (Roussel et al., 1994). Escherichia coli KW251 (Promega) and Sure (Stratagene) were used as recipient of recombinant $\lambda$ phages and plasmids, respectively. DNA fragments used as hybridization probes for genetic mapping studies are listed in Table 1.

DNA preparations, endonuclease restriction and gel electrophoresis. For high-molecular-mass DNA preparation, $S$. thermophilus cells were grown in modified M17 medium (Terzaghi \& Sandine, 1975) supplemented with $20 \mathrm{mM}$ DLthreonine and with chloramphenicol at a final concentration of $170 \mu \mathrm{g} \mathrm{ml}^{-1}$ during the last hour of incubation. The cells were mixed with low-melting-temperature agarose and further treated to purify DNA as described previously (Roussel et al., 1994). For use in conventional electrophoresis, DNA was prepared according to a modified version of the Marmur procedure (Colmin et al., 1991). Digestions using restriction endonucleases SmaI, BssHII and Sfil purchased from Boehringer Mannheim were performed as previously described (Roussel et al., 1994). High-molecular-mass fragments were separated by contour-clamped homogeneous electric field (CHEF) gel electrophoresis (Chu et al., 1986) in a CHEFDRII apparatus (Bio-Rad). Lambda DNA concatemers purchased from Bio-Rad and XhoI- or HindIII-digested lambda DNA were used as size markers. Fragments shorter than $30 \mathrm{~kb}$ were identified by conventional gel electrophoresis. Bacteriophage DNA was extracted according to Sambrook et al. (1989). Plasmid DNA was extracted by the alkaline lysis method described by Hopwood et al. (1985) and purified on a $\mathrm{CsCl}$ gradient.

Table 1. DNA fragments used for genetic mapping and assignment to the physical map of the CNRZ368 and NST2280 chromosomes

\begin{tabular}{|c|c|c|c|c|c|c|c|c|}
\hline \multirow[t]{3}{*}{ Probe* } & \multirow[t]{3}{*}{ Gene (function) } & \multirow[t]{3}{*}{ Reference/source } & \multicolumn{6}{|c|}{ Hybridizing fragments $\dagger$} \\
\hline & & & \multicolumn{3}{|c|}{ CNRZ368 } & \multicolumn{3}{|c|}{ NST2280 } \\
\hline & & & $S m a I$ & BssHII & $S f i \mathrm{I}$ & SmaI & BssHII & SfiI \\
\hline pNST21 & purA (adenylosuccinate synthetase) & Pébay et al. (1993) & 4 & 1 & 1 & 5 & 1 & 1 \\
\hline pEPK1 & $\begin{array}{l}\text { lacS (lactose permease) } \\
\text { galM (aldose 1-epimerase) } \\
\text { galE (UDPglucose 4-epimerase) }\end{array}$ & Poolman et al. (1990) & 1 & 2 & 5 & 6 & 2 & 2 \\
\hline pSth1 & ldh (L-lactate dehydrogenase) & $\begin{array}{l}\text { J. Delcour (Université Catholique de Louvain, } \\
\text { Belgium) } \ddagger\end{array}$ & 9 & 2 & 2 & 10 & 2 & 2 \\
\hline pTIL45 & pepC (aminopeptidase C) & Chapot-Chartier et al. (1994) & 3 & 4 & 1 & 2 & 4 & 1 \\
\hline pTG2215 & rec-like (DNA recombination) & A. Mercenier $\ddagger$ & 4 & 1 & 1 & 5 & 1 & 1 \\
\hline pVE1044 & $r e c A$ (DNA recombination) & Duwat et al. (1992) & 13 & 1 & 1 & 13 & 1 & 1 \\
\hline pR224 & bexA (DNA reparation) & Prudhomme et al. (1991) & 13 & ND & ND & 13 & ND & ND \\
\hline 141 & $23 \mathrm{~S}$ gene encoding rRNA & Pébay et al. (1992a) & $3,6,11,12,17,18$ & $1,4,5$ & ND & $2,7,11,12,16$ & $1,4,5$ & ND \\
\hline 143.1 & $16 \mathrm{~S}$ gene encoding rRNA & Pébay et al. (1992b) & $3,4,11,13,14,17$ & $1,4,5$ & ND & $2,5,11,13,14$ & $1,4,5$ & ND \\
\hline$\lambda$ NST19 & gor (glutathione reductase) & Pébay et al. (1995) & 6 & 5 & 1 & 7 & 5 & 1 \\
\hline ES & IS1191 (insertion sequence) & Guédon et al. (1995) & & & & & & \\
\hline $149.2 \$$ & IS981 (insertion sequence) & Guédon et al. (1995) & & & & & & \\
\hline ALS & aISS1 (insertion sequence) & Bourgoin et al. (1996) & & & & & & \\
\hline$\lambda \mathrm{NST} 101$ & IS1191, IS981 and unknown & Guédon et al. (1995) & 4 & 1 & 1 & ND & ND & ND \\
\hline $149 \|$ & IS $981, \alpha I S S 1$ and unknown & Bourgoin et al. (1996) & 2 & 2 & 2 & ND & ND & ND \\
\hline
\end{tabular}

ND, Not determined.

*All probes used were from $S$. thermophilus, with the exception of the pR224 probe, which was from Streptococcus pneumoniae.

† Fragment numbers refer to those given in Table 2 .

$\ddagger$ Personal communication.

$\$$ Hybridization data are given in Table 3 for the $\mathrm{E}, 149.2$ and $\mathrm{AL}$ probes.

$\|$ Probe that revealed several fragments of different intensities. For each of these probes, the most strongly revealed band is indicated. 
Fragment nomenclature. Each restriction fragment produced by digestion with a single endonuclease was denoted by the initial letter(s) of the enzyme used to produce it ( $\mathrm{Sm}$ for $S m a \mathrm{I}$; Sf for $S$ fiI ; and B for BssHII). Fragments produced by digestion with two endonucleases were denoted by the initial letters of the two enzymes (BSm for BssHII/SmaI; SfSm for Sfil/SmaI; and BSf for BssHII/Sfil). The fragments from each digest were numbered in order of decreasing size.

DNA Southern blot analysis. High-molecular-mass fragments separated by CHEF electrophoresis were transferred onto positively charged nylon membranes (Hybond $\mathrm{N}+$; Amersham) by alkaline Southern transfer (Reed \& Mann, 1985), whereas fragments separated by conventional electrophoresis were transferred onto nylon membranes (Hybond $\mathrm{N}$; Amersham) following the manufacturer's instructions. The probes were labelled by random priming systems with $\left[\alpha-{ }^{32} \mathrm{P}\right] \mathrm{dCTP}$ (Megaprime DNA labelling kit; Amersham) or with digoxigenin (Dig DNA Labelling and Detection kit; Boehringer Mannheim). Hybridizations were carried out as previously described by Larbi et al. (1990) for ${ }^{32} \mathrm{P}$-labelled probes or by following the manufacturer's instructions for Dig-labelled probes.

\section{RESULTS}

\section{PFGE of A054, CNRZ368 and NST2280 DNA digested with low-frequency-cutting restriction enzymes and estimation of their genomic sizes}

The three restriction endonucleases Sfil, BssHII and Smal previously used in the physical mapping of the $S$. thermophilus A054 chromosome (Roussel et al., 1994) were also used to digest the genomic DNA of strains CNRZ368 and NST2280. Fig. 1 displays the PFGE patterns of A054, CNRZ368 and NST2280 genomic DNA digested with $S m a I$. The similarity of the A054 and CNRZ368 SmaI PFGE patterns (lanes 1 and 2; 12 comigrating fragments among 15 ) suggests that only a slight genetic polymorphism exists between the two strains and probably involves a few regions in the chromosome. The comparison of A054 and NST2280 SmaI PFGE patterns (lanes 1 and 3; six comigrating fragments among 15) revealed a more important restriction polymorphism and suggested that the polymorphism between the two strains involves numerous regions of the chromosome. SmaI, Sfil and BssHII cleaved the DNA of CNRZ368 into 24, five and eight fragments and produced 21, four and eight fragments from NST2280 DNA, respectively (Table 2). Mean chromosome sizes have been estimated as $1864 \mathrm{~kb}$ for CNRZ368 and $1840 \mathrm{~kb}$ for NST2280 by summing-up fragment sizes obtained in single and double digestions.

\section{Comparison of the physical maps of the CNRZ368 and NST2280 chromosomes with that of A054}

Physical maps of the CNRZ368 and NST2280 chromosomes were established by using the strategy previously described for the map construction of the A054 strain (Roussel et al., 1994). The SfiI, SmaI and BssHII restriction sites were located by analysing partial digestion products with $S f \mathrm{I}$, by analysing double-digest patterns and by identifying cross-hybridizing fragments with DNA probes. Double digestions were performed

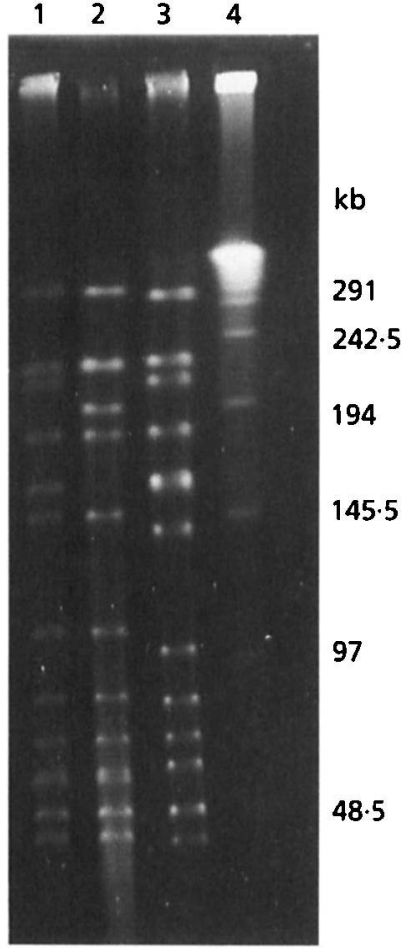

Fig. 1. PFGE gel (CHEF configuration) of Smal digests of genomic DNA of $S$. thermophilus strains. Lanes: 1, strain A054; 2, strain CNRZ368; 3, strain NST2280; 4, lambda DNA concatemers. The sizes of lambda DNA concatemers are given in $\mathrm{kb}$ on the right. The ramped pulse times were $5-15 \mathrm{~s}$ at $200 \mathrm{~V}$ for $27 \mathrm{~h}$. The gel was $1.0 \%$ SeaKem LE agarose in $0.5 \times$ TBE $(1 \times$ TBE is $0.1 \mathrm{M}$ Tris/borate, $0.2 \mathrm{mM}$ EDTA, $\mathrm{pH} 8$ ) held constant at $14^{\circ} \mathrm{C}$. With the conditions used, fragments with sizes smaller than $30 \mathrm{~kb}$ were not detectable in the gel but were observed by conventional electrophoresis.

according to two different procedures. The first method was simultaneous digestions and the second method was digestions of PFGE-purified fragments with a second restriction enzyme. Thirty-seven restriction sites were located on the physical map of CNRZ368:24 SmaI sites, eight BssHII sites and five SfiI sites (Fig. 2). Alignment of the CNRZ368 and A054 physical maps showed that the 37 restriction sites are conserved in the two strains. The $40 \mathrm{~kb}$ difference in the CNRZ368 and A054 genome sizes was found distributed into three variable regions, named var1A, var1B and var1C (Fig. 2). The polymorphic region var1A was detected within the BssHII-Sfi fragment BSf6 of CNRZ368 (common part of $\mathrm{B} 1$ and Sf4) where $6 \mathrm{~kb}$ is missing in comparison to the BSf6 fragment of A054. The variable region var1B was located in the BSm5 fragment (common part of $\mathrm{Sm} 2$ and B2) of CNRZ368 which has an additional $11 \mathrm{~kb}$. The third variable region (var1C) was located in the Sm4 fragment of CNRZ368 which contains an additional $35 \mathrm{~kb}$ sequence compared to the equivalent $\mathrm{Sm} 5$ fragment of A054.

Thirty-three restriction sites were located on the chromosomal map of NST2280: 21 SmaI sites, eight BssHII sites and four SfiI sites (Fig. 2). Alignment of NST2280 and 
Table 2. Size of the restriction fragments of S. thermophilus CNRZ368 and NST2280 DNA

The mean sizes for the CNRZ368 and NST2280 genomes were 1864 and $1840 \mathrm{~kb}$, respectively. Fragments in bold type have identical sizes to those of A054 DNA (Roussel et al., 1994). The sizes indicated are the mean of at least three independent experiments.

\begin{tabular}{|c|c|c|c|c|c|c|c|c|c|c|c|c|}
\hline \multirow[t]{2}{*}{ Band } & \multicolumn{6}{|c|}{ CNRZ368 } & \multicolumn{6}{|c|}{ NST2280 } \\
\hline & SmaI & sfi & BssHII & BssHII/SfiI & $S f \mathbf{i} / S_{m a I}$ & BssHII/SmaI & SmaI & SfiI & BssHII & BssHII/SfiI & $S f i 1 / S m a I$ & BssHII/Smal \\
\hline 1 & 324 & 828 & 671 & 360 & 223 & 234 & 302 & 789 & 634 & 383 & 221 & 302 \\
\hline 2 & 223 & 622 & 394 & 285 & 221 & 193 & 221 & 658 & 399 & 251 & 212 & 185 \\
\hline 3 & 221 & 261 & 320 & 261 & 193 & 182 & 212 & 239 & 333 & 239 & 185 & 158 \\
\hline 4 & 193 & 138 & 180 & 197 & 172 & 130 & 185 & 157 & 181 & 210 & 158 & 130 \\
\hline 5 & 182 & $18 \cdot 1$ & 125 & 180 & 146 & 127 & 158 & & 119 & 181 & 140 & 116 \\
\hline 6 & 146 & & 68 & 128 & 138 & 107 & 158 & & 68 & 147 & 116 & 107 \\
\hline 7 & 107 & & 64 & 125 & 107 & 96 & 140 & & 64 & 124 & 100 & 100 \\
\hline 8 & 85 & & 48 & 124 & 98 & 94 & 100 & & 48 & 119 & 96 & 90 \\
\hline 9 & 72 & & & 68 & 85 & 85 & 82 & & & 68 & 94 & 82 \\
\hline 10 & 61 & & & 64 & 72 & 72 & 72 & & & 64 & 85 & 72 \\
\hline 11 & 58 & & & 48 & 65 & 68 & 65 & & & 48 & 82 & 68 \\
\hline 12 & 46 & & & 18.1 & 61 & 64 & 46 & & & $12 \cdot 2$ & 72 & 64 \\
\hline 13 & 46 & & & $12 \cdot 2$ & 58 & 61 & 46 & & & & 65 & 55 \\
\hline 14 & 38 & & & & 46 & 48 & 33 & & & & 63 & 48 \\
\hline 15 & 36 & & & & 46 & 46 & $9 \cdot 2$ & & & & 46 & 47 \\
\hline 16 & $9 \cdot 2$ & & & & 36 & 46 & 3.34 & & & & 46 & 46 \\
\hline 17 & 4.85 & & & & 30 & 40 & $0.91^{*}$ & & & & 24 & 46 \\
\hline 18 & $3 \cdot 34$ & & & & $18 \cdot 1$ & 38 & & & & & $9 \cdot 2$ & 33 \\
\hline 19 & $0.91 \dagger$ & & & & $9 \cdot 2$ & 36 & & & & & 8.9 & 24 \\
\hline 20 & & & & & 8.5 & 24 & & & & & $3 \cdot 34$ & 24 \\
\hline 21 & & & & & 8.5 & 24 & & & & & $0.91^{*}$ & 19 \\
\hline 22 & & & & & $4 \cdot 85$ & 19 & & & & & & $9 \cdot 2$ \\
\hline 23 & & & & & $3 \cdot 34$ & $9 \cdot 2$ & & & & & & 5.80 \\
\hline 24 & & & & & $0.91 \dagger$ & $5 \cdot 80$ & & & & & & $3 \cdot 34$ \\
\hline 25 & & & & & & 4.85 & & & & & & $0.91^{*}$ \\
\hline 26 & & & & & & $3 \cdot 34$ & & & & & & \\
\hline 27 & & & & & & $0.91 \dagger$ & & & & & & \\
\hline $\begin{array}{c}\text { Genome size } \\
(k b)\end{array}$ & 1861 & 1867 & 1870 & 1870 & 1855 & 1863 & 1837 & 1843 & 1846 & 1846 & 1831 & 1839 \\
\hline
\end{tabular}

*Presence of five $0.91 \mathrm{~kb}$ fragments.

†Presence of six $0.91 \mathrm{~kb}$ fragments.

A054 physical maps allowed 15 variable loci to be detected. They were named var $2 A-v a r 2 O$. Eleven of them correspond to the modification in the size of a fragment delimited by conserved restriction sites. These variable regions are var $2 A, \operatorname{var} 2 B, \operatorname{var} 2 C$, var $2 D$, var $2 G$, var $2 I$, var $2 J$, var $2 L$, var $2 M$, var $2 N$ and var $2 O$ (Fig. 2 ). The small difference of $0.4 \mathrm{~kb}$ detected in var $2 \mathrm{O}$ between the Sm14 fragments was determined by analysing conventional electrophoresis patterns of double digestions with Sfil/SmaI. The $8.5 \mathrm{~kb}$ fragment of A054 (SfSm20) is replaced by a fragment of $8.9 \mathrm{~kb}$ in the genome of strain NST2280. Other size differences estimated by comparing the fragment sizes determined by PFGE extend from $3 \mathrm{~kb}$ to $13 \mathrm{~kb}$. Physical map comparison also allowed us to detect the appearance and disappearance of $S m a \mathrm{I}, B s s \mathrm{HII}$ or Sfil restriction sites in the variable regions var $2 E$, var $2 F, \operatorname{var} 2 H, \operatorname{var} 2 K$ and var $2 M$ of the NST 2280 chromosome (Fig. 2). var $2 M$ is a variable region which shows a modification of its size and the disappearance of two Smal sites.

\section{Comparison of the genetic maps of the CNRZ368 and NST2280 chromosomes with that of A054}

The lacS, galE, galM, ldh, gor, pepC, recA, hexA, reclike, purA and $r r n$ genes were located on the physical maps of the CNRZ368 and NST2280 chromosomes by hybridizing gene-specific probes to $S m a \mathrm{I}, B s s \mathrm{HII}$ and $S f \mathrm{I}$ patterns. The probes used and the fragments to which they hybridized are listed in Table 1. Both 16S-specific probe I43.1 and 23S-specific probe I41 were used to locate the $r r n$ loci. Each of these genes was found to have the same location in the chromosome of the three strains within the limits of precision of the genetic mapping experiments (Fig. 2). The only difference in the genetic organization was the presence of five $r r n$ loci in the chromosome of NST2280 instead of the six in the A054 and CNRZ368 chromosomes. We demonstrated that the NST2280 strain contained five $r r n$ loci whereas the NST7 strain from which it is derived was previously shown to contain six rrn loci (Pébay et al., 1992b). The $r r n D-r r n E$ tandem in the NST7 strain had been replaced by the single $r r n$ locus in the NST2280 strain. The deletion event removes the sequence containing the $3^{\prime}$ extremity of the $r r n D$ locus, the interoperonic region and the $5^{\prime}$ extremity of the $r r n E$ locus corresponding to the $6 \mathrm{~kb}$ variable locus var $2 M$.

\section{Location of IS981 copies}

The number and location of IS981 copies in the chromosome of the three strains A054, CNRZ368 and NST2280 were determined by hybridizing the IS981specific probe I49.2 to conventional and PFGE restric- 

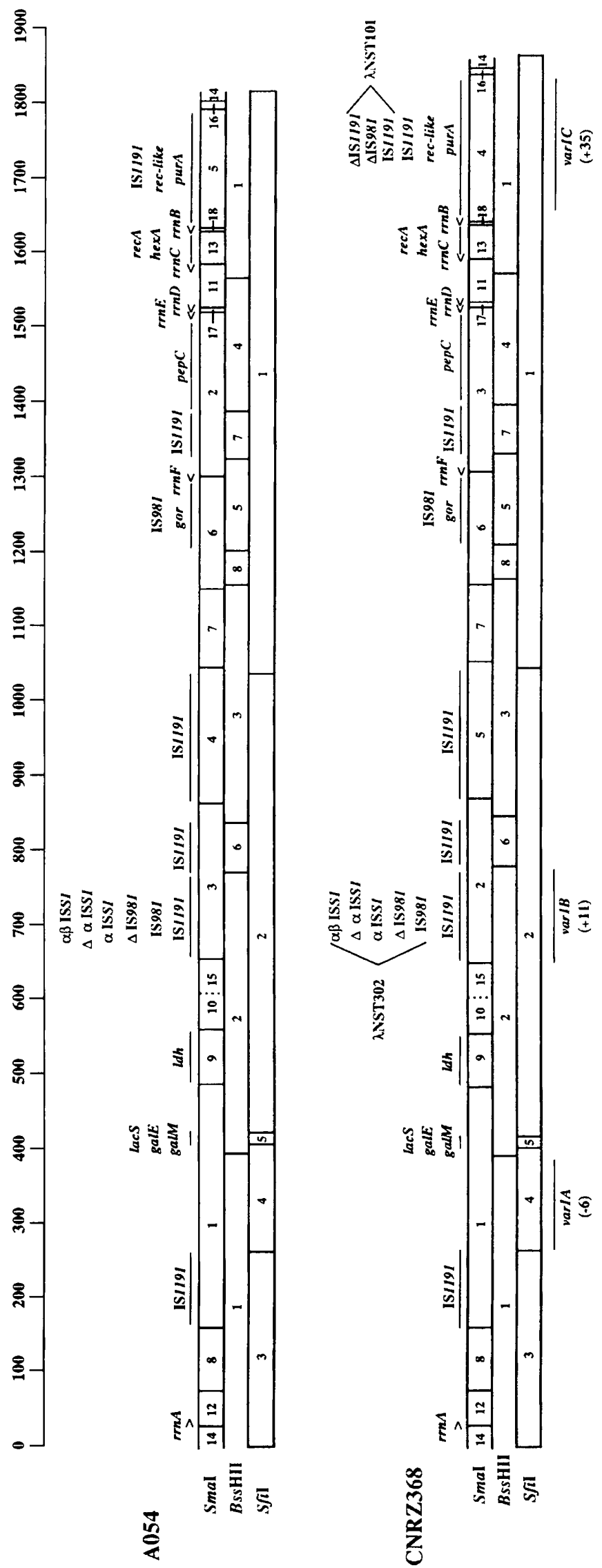

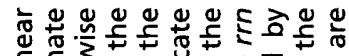

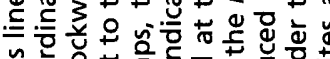

\% 웅은

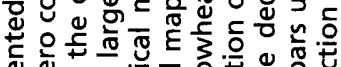

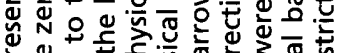

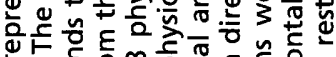

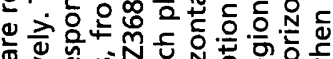

等

空

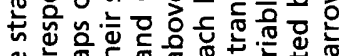

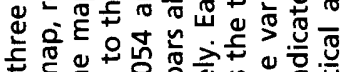

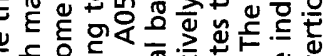

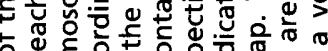

4

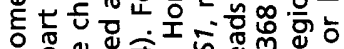

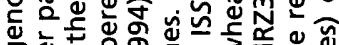

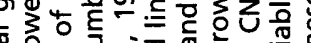

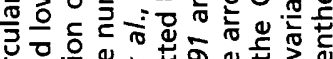

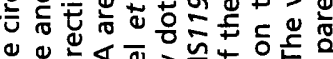

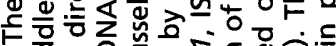

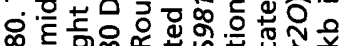

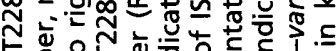

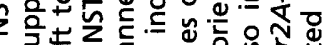

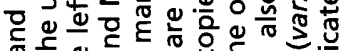

$\infty$

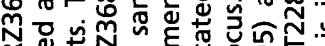

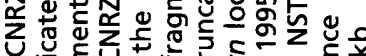

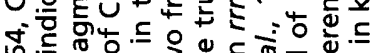

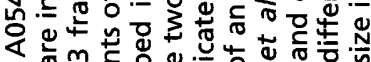

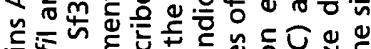

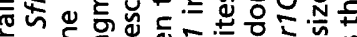

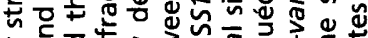

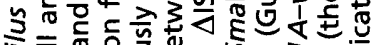

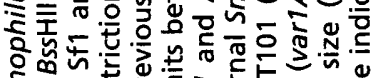

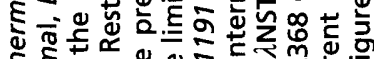

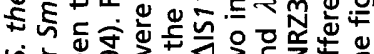

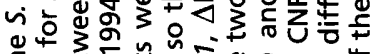

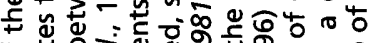

衰装

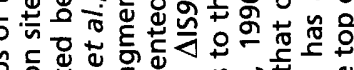

然.

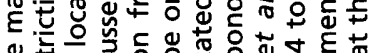

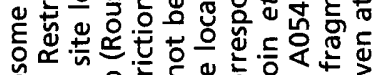

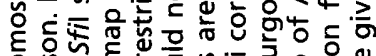

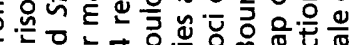

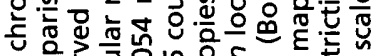

过

फ \&

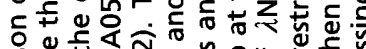

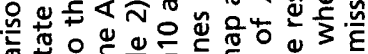

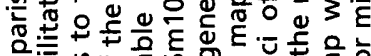

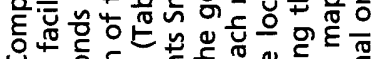

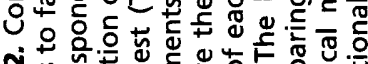

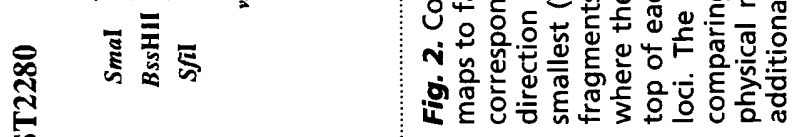


Table 3. Hybridization results of the E probe (specific to I51191), the 149.2 probe (specific to IS981) and the AL probe (specific to alSS1) with restriction fragments of $S$. thermophilus A054, CNRZ368 and NST2280 DNA

\begin{tabular}{|c|c|c|c|c|c|c|c|c|c|c|c|c|c|c|c|}
\hline & \multicolumn{5}{|c|}{ A054 } & \multicolumn{5}{|c|}{ CNRZ368 } & \multicolumn{5}{|c|}{ NST2280 } \\
\hline & SmaI & BssHII & SfiI & BssHII/SmaI & Sfil/SmaI & SmaI & BssHII & $S f i \mathrm{I}$ & BssHII/SmaI & $S f i \mathrm{I} / S_{m a I}$ & SmaI & BssHII & $S_{f i I}$ & BssHII/SmaI & $S f i l / S m a I$ \\
\hline \multirow[t]{6}{*}{ IS 1191} & $\mathrm{Sm} 1$ & B1 & Sf1 & $\mathrm{BSm} 1$ & $\mathrm{Sm} 2$ & $\mathrm{Sm} 1$ & B1 & Sf 1 & BSm1 & $\mathrm{Sm} 2$ & Sm1 & B1 & Sf 1 & $\mathrm{Sm} 1$ & $\mathrm{Sm} 2$ \\
\hline & $\mathrm{Sm} 2$ & B2 & Sf2 & Sm4 & $\mathrm{Sm} 3$ & $\operatorname{Sm} 2$ & B2 & $\mathrm{Sf} 2$ & $\mathrm{Sm} 4^{*}$ & $\mathrm{Sm} 3$ & $\operatorname{Sm} 2$ & B2 & Sf 2 & $\mathrm{Sm} 4$ & $\operatorname{Sm} 3$ \\
\hline & $\mathrm{Sm} 3$ & B3 & $\mathrm{Sf} 3$ & Sm5 & SfSm3 & $\mathrm{Sm} 3$ & B3 & $\mathrm{Sf} 3$ & $\operatorname{Sm} 5$ & Sm4 & $\sin 3$ & B3 & Sf 3 & $\operatorname{Sm} 5$ & SfSm 3 \\
\hline & $\mathrm{Sm} 4$ & B6 & & $\mathrm{BSm} 5$ & Sm5 & Sm4 & B6 & & $\mathrm{BSm} 5$ & $\mathrm{SfS} m 4$ & $\mathrm{Sm} 4$ & B6 & & BSm6 & $\operatorname{Sm} 5$ \\
\hline & $\mathrm{Sm} 5$ & B7 & & B6 & SfSm8 & $\operatorname{Sm} 5$ & B7 & & B6 & SfSm8 & $\mathrm{Sm} 5$ & B7 & & B6 & SfSm10 \\
\hline & & & & B7 & & & & & B7 & & & & & B7 & \\
\hline \multirow[t]{3}{*}{ IS981 } & $\mathrm{Sm} 3^{*}$ & B2 & Sf1 & $\mathrm{BS} m 5^{*}$ & $\operatorname{Sm} 3$ & $\mathrm{Sm} 2^{*}$ & B1 & Sf1 & $\mathrm{BS} 5^{*}$ & $\mathrm{Sm} 2$ & ND & ND & $\mathrm{ND}$ & ND & ND \\
\hline & Sm6 & B5 & Sf 2 & Bsm7 & Sm6 & Sm4 & B2 & $\mathrm{Sf} 2$ & $\mathrm{Sm} 4$ & $\mathrm{Sm} 4$ & & & & & \\
\hline & & & & & & Sm6 & B5 & & $\mathrm{Bsm} 7$ & $\operatorname{Sin} 6$ & & & & & \\
\hline$\alpha[S S 1$ & $\mathrm{Sm} 3$ & NT & NT & NT & $\mathrm{NT}$ & $\operatorname{Sin} 2$ & NT & NT & $\mathrm{NT}$ & $\mathrm{NT}$ & $\mathrm{Sm} 3$ & NT & NT & NT & NT \\
\hline
\end{tabular}

ND, Not detected; NT, not tested.

"Fragments revealed with a higher intensity than the other fragments of the pattern.

tion patterns. CNRZ368 DNA digestions with five different restriction enzymes (Asp700, CfoI, Eco0109, EcoRI and EcoRV) revealed four hybridizing bands instead of three in the case of A054. Since these highfrequency-cutting restriction endonucleases do not cut within the probe, the chromosomes of A054 and CNRZ368 would contain three and four copies of IS981, respectively. For the five enzymes tested, the A054 and CNRZ368 restiction patterns showed three comigrating bands, strongly indicating that three IS981 copies have an identical location in the map of the two strains. For each enzyme, the additional band revealed in CNRZ368 DNA was shown to carry the truncated copy of IS981 previously cloned into $\lambda$ NST101 (Guédon et al., 1995). Hybridization of the I49.2 probe to $S m a \mathrm{I}, B s s \mathrm{HII}, S f \mathrm{I}$, Bss HII/SmaI and Sfil/SmaI product digestions revealed the presence of two and three fragments bearing IS981 copies in A054 and CNRZ368 DNA, respectively (Table $3)$. However, a higher intensity was obtained for the $\mathrm{Sm} 3$ and BSm 5 (common part of $\mathrm{Sm} 3$ and B2) fragments of A054 and for the Sm2 and BSm5 (common part of Sm2 and B2) fragments of CNRZ368 in the SmaI and $B s s \mathrm{HII} / S m a \mathrm{I}$ digests, respectively. These data suggested the presence of at least two copies of IS981 in this region of both the A054 and CNRZ368 chromosomes. Two IS981 copies from the BSm5 fragment of CNRZ368 were found within a $12 \mathrm{~kb}$ region which is included in the insert of $\lambda$ NST302 (Bourgoin et al., 1996). The location of the IS981 copies on the chromosomal map of strains A054 and CNRZ368 is indicated in Fig. 2. The I49.2 probe did not hybridize with the DNA of strain NST2280, indicating the absence of IS981 in this strain.

\section{Location of IS1191 copies}

The E probe which is included in the IS1191 element cloned into 2 NST101 (Guédon et al., 1995) was used to count and locate IS1191 copies. Hybridization of the E probe to CfoI-, DraI-, Eco0109- or HaeIII-digested DNA from A054 and CNRZ368 revealed seven and eight bands, respectively. Six bands were revealed when the E probe was hybridized to NST2280 DNA digested with CfoI, ClaI, Eco0109 or DraI. As these high-frequencycutting enzymes do not cut within the probe, A054, CNRZ368 and NST2280 DNA would contain seven, eight and six copies of IS1191, respectively. For the four enzymes tested, both A054 and CNRZ368 hybridization patterns showed seven comigrating bands, strongly suggesting that the seven IS1191 copies have an identical location in the map of the two strains. The additional band only revealed in CNRZ368 DNA was shown to bear the IS1191 copy cloned into $\lambda$ NST101. I73 and I74 are two adjacent $E c o$ RI fragments which were subcloned from $\lambda$ NST101 and sequenced (Guédon et al., 1995). I73 carries a complete IS1191 copy inserted in a truncated IS981 element and I74 carries a truncated copy of IS1191 which is not revealed by the $E$ probe. Hybridization of I73 and I74 to genomic DNA digested with EcoRI and EcoRV showed that this $4.4 \mathrm{~kb}$ sequence of the CNRZ368 chromosome was completely absent in the A054 and NST2280 DNA.

In order to locate the different copies of IS1191 on the chromosomal map of the three strains, the E probe was hybridized to SmaI, BssHII, SfiI, BssHII/SmaI and $S$ fil/SmaI restriction patterns. Hybridization on the BssHII/SmaI pattern revealed six fragments containing IS1191 copies for each of the three strains (Table 3), indicating the location of at least six copies of IS1191. Moreover, the Sm4 fragment of CNRZ368 was revealed with greater intensity by the $\mathrm{E}$ probe than the five other fragments, suggesting that this $\mathrm{Sm} 4$ fragment could carry at least two IS1191 copies. The location of $\lambda$ NST101 on the Sm4 fragment of CNRZ368 confirmed that this fragment contains the supplementary copy of $\lambda$ NST101. The location of the IS1191 copies on the chromosomal maps of the three strains is indicated in Fig. 2. Although high-frequency-cutting enzyme data indicated the presence of seven and eight IS1191 copies, only six and seven copies were located on the A054 and CNRZ368 maps, respectively. This suggests that another fragment could bear two IS1191 copies. The six copies of IS1191 in the NST2280 chromosome had 
similar locations in the A054 and CNRZ368 chromosomes, suggesting that they could be the same copies.

\section{Location of ISS1 copies}

Two different groups of iso-ISS1 elements ( $\alpha$ and $\beta$ ) were found in both Lactococcus lactis and S. thermophilus (Bourgoin et al., 1996). The AL probe which is an AluI fragment of pNST49 was used to count and locate the different $\alpha$ ISS1 copies in the chromosome of the three strains. Hybridization of the AL probe to DraI- and EcoRI-digested DNA of A054, CNRZ368 and NST2280 revealed three, three and one bands, respectively. As these enzymes do not cut within the probe, A054, CNRZ368 and NST2280 would contain three, three and one copies of $\alpha$ ISS1, respectively. The sizes of the three bands revealed by the AL probe on the A054 and CNRZ368 patterns are the same, suggesting that the three $\alpha$ ISS1 copies have an identical location on the chromosome of the two strains. The recombinant clone גNST302 isolated from a gene library of CNRZ368 was previously shown to contain three copies of the ISS1 element; two of them belong to the $\alpha$ subgroup and the third is an $\alpha \beta$ mosaic element called ISS1SC (Bourgoin et al., 1996). The three ISS1 copies are located in the $12 \mathrm{~kb}$ region which also contains two IS981 copies. No $\beta$ ISS1 element was found in NST2280 and ISS1SC was the only $\beta$ ISS1 element found in A054 and CNRZ368 DNA (Bourgoin et al., 1996). In order to locate the three copies of the $\alpha$ ISS1 element on the chromosomal map, the AL probe was hybridized to $S m a$ l patterns of the three strains. Only one fragment was revealed for each strain (Sm3, Sm2 and Sm3 for A054, CNRZ368 and NST2280, respectively). A more precise location of the three ISS1 copies on the physical maps of A054 and CNRZ368 was determined by using I49, a $6 \mathrm{~kb} E c o$ RI fragment of גNST302 (Guédon et al., 1995), as a probe. This probe revealed the $\mathrm{BSm} 5$ fragments, which are the common parts of Sm3 and B2 for A054 and of Sm2 and B2 for CNRZ368.

\section{DISCUSSION}

In this work, we have analysed the genetic polymorphism existing between three S. thermophilus strains by PFGE. The size of the chromosomes of strains CNRZ368 and NST2280 has been estimated at 1864 and $1840 \mathrm{~kb}$, respectively. These sizes are very close to those previously found for the A054 strain (1824 kb; Roussel et al., 1994). However, comparison of chromosome sizes is not a good indicator of genetic polymorphism. In the case of the three studied strains, the comparison of fingerprints obtained with both high-frequency-cutting enzymes or low-frequency-cutting enzymes revealed that CNRZ368 and A054 are very closely related to each other, and both are less closely related to NST2280.

The two strains A054 and CNRZ368 have chromosomes with similar restriction maps. All the 37 mapped sites (SmaI, SfiI and BssHII) were found to be conserved. The only differences detected were the sizes of three restriction fragments located in the variable regions var1 A, var $1 B$ and var $1 C$. These modifications can be explained by the insertion or deletion of sequences in the chromosome of CNRZ368 or A054. The alignment of the NST2280 physical map with that of A054 revealed 15 variable loci which were found to be distributed all along the chromosome. Among them, 11 variable regions correspond to restriction fragments with modified size and five variable regions have additional or missing mapped restriction sites compared with the map of A054. The appearance or disappearance of restriction sites in the NST2280 chromosome can be explained either by point mutation within the restriction site or by insertion or deletion of a sequence containing a mapped site. For the var $2 M$ region, the disappearance of two Smal sites is associated with the deletion of a $6 \mathrm{~kb}$ sequence containing these two $S m a \mathrm{I}$ sites (see later).

Comparison of gene locations in strains A054, CNRZ368 and NST2280 showed that the genetic organization is similar within these strains. Because A054 and CNRZ368 have very similar physical maps, a conserved genetic organization was expected. The 10 single-copy genes and the six rrn loci share identical positions on the chromosomes. The only differences detected between these two strains were two additional copies of IS1191 and one additional copy of IS981 present in the variable region var1C of CNRZ368. The location of the five other copies of IS1191, the three other copies of IS981 and the three copies of ISS1 were found to be the same. When the location of markers on the NST2280 chromosome was compared with that of the A054 chromosome, more differences were detected. The NST2280 chromosome was found to contain five $r r n$ loci instead of six, the $r r n D-r r n E$ tandem being replaced by a single rrn locus. A homologous recombination between the two $r r n$ loci of the original tandem probably resulted in the deletion of one $r r n$ locus and the interoperonic region. The loss of one $r r n$ locus from the tandem $r r n$ locus has already been observed in the progeny of the CNRZ368 (Pébay et al., 1992b) and A054 (Roussel et al., 1994) strains. In the chromosome of the NST2280 strain, no copy of the element IS981 was detected and only a single copy of ISS1 was found instead of three in the two other strains.

In other bacteria, variability of genetic organization has also been analysed by comparing their physical and genetic maps. In some bacterial species, genetic maps are not conserved; for example, comparison of the genetic maps of the larger replicons of two Leptospira interrogans serovars showed evidence of large rearrangements (Zuerner et al., 1993). However, comparative studies of chromosomal maps in Mycoplasma mycoides (Pyle et al., 1990) and Mycoplasma hominis species (Ladefoged \& Christiansen, 1992) revealed a conserved location of the mapped genes as well as between two strains each of Pseudomonas aeruginosa (Schmidt et al., 1996) and Thermus thermophilus (Tabata \& Hoshino, 1996). Conservation of the gene order was also found when the genetic maps from 22 Lyme disease agents (Borrelia burgdorferi) were compared (Casjens et al., 1995). Comparison of the physical 
and genetic maps of eight Clostridium perfringens strains also showed a similar genetic organization in seven of them. Three hypervariable regions were detected and found to be associated with a virulence gene or with an enterotoxin gene (Canard et al., 1992). A comparative analysis of five physical maps of different $E$. coli strains with that of E. coli MG1655 revealed 41 variable regions (Perkins et al., 1993). Whereas some of these modifications could be explained by rearrangements involving repeated sequences ( $r r n$ loci and IS elements), or by the movement of bacteriophages, the majority of variations had unknown causes.

Because of their ability to cause rearrangements such as insertions, inversions or deletions, IS elements were suspected to contribute to the genetic variability observed between the three $S$. thermophilus strains. The two polymorphic regions var1B and var1C are associated with IS elements in the CNRZ368 chromosome. Indeed, the $\mathrm{BSm} 5$ fragment (common region of $\mathrm{Sm} 2$ and B2) carries the variable region $\operatorname{var} 1 B$ as well as two copies of IS981 elements, one copy of IS1191 and the three copies of ISS1 (Fig. 2). The $12 \mathrm{~kb}$ region of 2NST302 containing the two copies of IS981 and the three copies of ISS1 was shown to be present in the A054 chromosome, indicating that IS981 and ISS1 elements were not responsible for the variability observed in var1B. The quasi-identity of IS981 and ISS1 element sequences between $S$. thermophilus and Lactococcus lactis and their distribution in the two species suggest recent horizontal transfer of these elements from $L$. lactis to $S$. thermophilus (Bourgoin et al., 1996; Guédon et al., 1995). The $12 \mathrm{~kb}$ chromosomal region which seems to be absent in almost all of the S. thermophilus strains tested could result from the integration of a lactococcal DNA fragment already containing the IS elements into the chromosome of the common ancestor of A054 and CNRZ368. In the Sm4 fragment of the CNRZ368 chromosome, two additional copies of IS1191 and one additional copy of IS981 are detected in the variable region var1C. We showed that these IS copies were present in var $1 \mathrm{C}$ included in a $4.4 \mathrm{~kb}$ fragment of CNRZ368, which is completely absent in the A054 and NST2280 chromosomes. Whilst these three IS copies were shown to participate in the variability observed in var1C, they are not directly responsible for the observed modification. It is tempting to speculate that the $4.4 \mathrm{~kb}$ sequence is a part of the $35 \mathrm{~kb}$ which could be a temperate bacteriophage or a transposon inserted in the var1C region.

Our study is a first step in the analysis of the intraspecific variability within $S$. thermophilus species. The nature and the origin of the sequences present in the variable regions have to be further analysed to understand the speciation process in the species.

\section{ACKNOWLEDGEMENTS}

We are grateful to the scientists who kindly supplied cloned genes and probes: A. Mercenier for the rec-like probe, J. Delcour for the $l d b$ probe, A. Gruss for the recA probe, B. Poolman for the gal probe, J.P. Claverys for the hexA probe and M.P. Chartier for the $p e p C$ probe. Y.R. was supported by a fellowship from the Ministère de la Recherche et de la Technologie. We thank Lois Silk and Huw Parry for reading the manuscript.

\section{REFERENCES}

Bourgoin, F., Guédon, G., Pébay, M., Roussel, Y., Panis, C. \& Decaris, B. (1996). Characterization of a mosaic ISS1 element and evidence for the recent horizontal transfer of two different types of ISS1 between Streptococcus thermophilus and Lactococcus lactis. Gene 178, 15-23.

Canard, B., Saint-Joanis, B. \& Cole, S. T. (1992). Genomic diversity and organization of virulence genes in the pathogenic anaerobe Clostridium perfringens. Mol Microbiol 6, 1421-1429.

Casjens, S., Delange, M., Ley, H. L., Rosa, P. \& Huang, W. M. (1995). Linear chromosomes of Lyme disease agent spirochetes: genetic diversity and conservation of gene order. J Bacteriol 177, 2769-2780.

Chapot-Chartier, M. P., Rul, F., Nardi, M. \& Gripon, J. C. (1994). Gene cloning and characterization of PepC, a cysteine aminopeptidase from Streptococcus thermophilus, with sequence similarity to the eucaryotic bleomycin hydrolase. Eur J Biochem 224, 497-506.

Chu, G., Vollrath, D. \& Davis, R. W. (1986). Separation of large DNA molecules by contour-clamped homogeneous electric fields. Science 234, 1582-1585.

Colmin, C., Larbi, D., Simonet, J.-M. \& Decaris, B. (1987). Strain identification in the genus Streptococcus by DNA restriction analysis. FEMS Microbiol Rev 46, 14.

Colmin, C., Pébay, M., Simonet, J.-M. \& Decaris, B. (1991). A species-specific DNA probe obtained from Streptococcus salivarius subsp. thermophilus detects strain restriction polymorphism. FEMS Microbiol Lett 81, 123-128.

Duwat, P., Ehrlich, S. D. \& Gruss, A. (1992). A general method for cloning recA genes of Gram-positive bacteria by polymerase chain reaction. J Bacteriol 174, 5171-5175.

Guédon, G., Bourgoin, F., Pébay, M., Roussel, Y., Colmin, C., Simonet, J.-M. \& Decaris, B. (1995). Characterization and distribution of two insertion sequences, IS1191 and iso-IS981, in Streptococcus thermophilus: does intergeneric transfer of ISs occur in lactic acid bacteria co-cultures? Mol Microbiol 16, 69-78.

Hopwood, D. A., Bibb, M. J., Chater, K. F., Kieser, T., Bruton, C. J., Kieser, H. M., Lydiate, D. J., Smith, C. P., Ward, J. M. \& Schrempf, H. (1985). Genetic Manipulation of Streptomyces: a Laboratory Manual. Norwich: John Innes Foundation.

Ladefoged, S. A. \& Christiansen, G. (1992). Physical and genetic mapping of the genomes of five Mycoplasma hominis strains by pulsed-field gel electrophoresis. J Bacteriol 174, 2199-2207.

Larbi, D., Colmin, C., Rousselle, L., Decaris, B. \& Simonet, J.-M. (1990). Genetic and biological characterization of nine Streptococcus thermophilus bacteriophages. Lait 70, 107-116.

Pébay, M., Colmin, C., Guédon, G., De Gaspéri, C., Decaris, B. \& Simonet, J.-M. (1992a). Detection of intraspecific DNA polymorphism in Streptococcus salivarius subsp. thermophilus by a homologous rDNA probe. Res Microbiol 143, 37-46.

Pébay, M., Roussel, Y., Simonet, J.-M. \& Decaris, B. (1992b). Highfrequency deletion involving closely spaced $\mathrm{rRNA}$ gene sets in Streptococcus thermophilus. FEMS Microbiol Lett 98, 51-56.

Pébay, M., Colmin, C., Guédon, G., Simonet, J.-M. \& Decaris, B. (1993). Chromosomal genetic instability in Streptococcus thermophilus. Lait 73, 181-190. 
Pébay, M., Holl, A.-C., Simonet, J.-M. \& Decaris, B. (1995). Characterization of the gor gene of the lactic acid bacterium Streptococcus thermophilus CNRZ368. Res Microbiol 146, 371-383.

Perkins, J. D., Heath, J. D., Sharma, B. R. \& Weinstock, G. M. (1993). XbaI and BlnI genomic cleavage maps of Escherichia coli K-12 strain MG1655 and comparative analysis of other strains. $J$ Mol Biol 232, 419-445.

Poolman, B., Royer, T. J., Mainzer, S. E. \& Schmidt, B. F. (1990). Carbohydrate utilization in Streptococcus thermophilus: characterization of the genes for aldose 1-epimerase (mutarotase) and UDPglucose 4-epimerase. J Bacteriol 172, 4037-4047.

Prudhomme, M., Méjean, V., Martin, V. \& Claverys, J.-P. (1991). Mismatch repair genes of Streptococcus pneumoniae: HexA confers a mutator phenotype in Escherichia coli by negative complementation. J Bacteriol 173, 7196-7203.

Pyle, L. E., Taylor, T. \& Finch, L. R. (1990). Genomic maps of some strains within the Mycoplasma mycoides cluster. J Bacteriol 172, 7265-7268.

Reed, K. C. \& Mann, D. A. (1985). Rapid transfer of DNA from agarose gels to nylon membranes. Nucleic Acids Res 13, 7207-7221.

Roussel, Y., Pébay, M., Guédon, G., Simonet, J.-M. \& Decaris, B. (1994). Physical and genetic map of Streptococcus thermophilus A054. J Bacteriol 176, 7413-7422.
Salzano, G., Moschetti, G., Villani, F. \& Coppola, S. (1993). Biotyping of Streptococcus thermophilus strains by DNA fingerprinting. Res Microbiol 144, 381-387.

Sambrook, J., Fritsch, E. F. \& Maniatis, T. (1989). Molecular Cloning: a Laboratory Manual, 2nd edn. Cold Spring Harbor, NY : Cold Spring Harbor Laboratory.

Schmidt, K. D., Tummler, B. \& Römling, U. (1996). Comparative genome mapping of Pseudomonas aeruginosa PAO with $P$. aeruginosa $\mathrm{C}$, which belongs to a major clone in cystic fibrosis patients and aquatic habitats. J Bacteriol 178, 85-93.

Tabata, K. \& Hoshino, T. (1996). Mapping of 61 genes on the refined physical map of the chromosome of Thermus thermophilus HB27 and comparison of genome organization with that of T. thermophilus HB8. Microbiology 142, 401-410.

Terzaghi, B. E. \& Sandine, W. E. (1975). Improved medium for lactic streptococci and their bacteriophages. Appl Microbiol 29, 807-813.

Zuerner, R. L., Herrmann, J. L. \& Saint Girons, I. (1993). Comparison of genetics maps for two Leptospira interrogans serovars provides evidence for two chromosomes and intraspecies heterogeneity. J Bacteriol 175, 5445-5451.

Received 6 September 1996; revised 4 November 1996; accepted 8 November 1996. 